:speriment on the independent nature of the ierebral vessels; animals have been bled to leath, yet cerebral congestions have survivid the general loss of blood. It is possible hat the cerebrum might thas be even furher oppressed. In this indirect manner may debility, indeed, be said to cause amaurosis, yet it is by inducing or augmenting local congestion.

In the same manner the amaurosis with hæmorrhage, protiacted suckling, \&c. is explicable, -in typhus the congestion is erident.

The natural tendency of suppressed evacrations is also to produce congestions else. where. In this way would $I$ explain the amaurotic affections with suspension of wonted discharges, $c . g$. of the secretion of milk; the bleeding of hæmorrhoids; also from the healing of old ulcers, and retention of the catamenia, congestion of the optic apparatus being thus occasioned.

In all cases of symptomatic amaurosis the following indications are, therefore, obvious, bamely, to treat these congestions by local derivatives, combined, in the phlogistic diathesis, with venesection, purgatives, and the preparations of mercury; but in cases with debility, with the seasonable administration of general tonics ; in each case after the removal of the primary irritant by appropriate eracuants.

This local antiphlogistic treatment, thus advised in all cases, with or without debility, may be employed when it is too late. The issue of repeated neglect of the congestire stage may be that of disorganisation, or paralysis of the nervous structure of vision. Here we may try collyria, with strychnine, or frictions, with the sane behind the ears; but the stage of paralysis being arrived, I fully agree with Mr. Travers, that the disease will be aggravated by the loss of blood, topical or general.

ln cases with debility, I fear that the use of tonics has been unjustly suspected by Beer, who adduces, as the effect of the calamus aromaticus, when there is a tendency to pectoral complaints,--of bark, in costive habits, and of steel, when combined with narcotics, \&c., an increased determination of blood to the eyes, thus quickly aggravating the amaurosis.

Had there been previously a due regulation of the digestive functions, and, at the same time, topical abstraction of blood, I believe in no instance would tonics be found to injure in feeble habits; but, on the contrary, I have found the greatest possible advantage thence derived. It will be noticed, that in speaking of topical applications thronghout this paper, I mean those applied near to the eye.

It is not my intention at present to enter into those cases of amaurosis not oricinating spmpathetically, but being primarily orgauic; e.g. from medullary tungus, morbid changes in the thalami, optic nerves, retina, exostosis at the basis cranii, or that depending on disease of the fifth pair, as shown by Magendie. 'These are, for the most part, incurable; it now only remains for me to account for the supposed success of the continental practice-emetics.

The cases must have been merely recent symptomatic congestions, such as frequently arise purely from a loaded stomach. Here emetics may succeed, but yet only as evacuants of the primary irritant. However, from the case recorded above, it will appear that the amaurotic affection frequently survives the removal of the remote irritant by evacuants, whether emetics, enemas, or both, although removeable thereby when the affection is purely sympathetic. But the tendency to degenerate into secondarily organic disease being established, and in these mixed cases the best evacuant addressed to the primary irritation being insufficient, when we consider conjointly with this fact, the peculiarity appended to the evacuant power of an emetic, that of aggravating the now secondarily organic affection by further congestion, it will be evident that we should aspire to procure an ultimate good at less expense. A balance of advantage can only possibly result in such cases as are assuredly and purely sympathetic, originating in a foul condition of the stomach. Even in such I fully accord with $\mathrm{Mr}$. Travers, that the exhibition of blue-pill, saline aperients, and mild tonics, will produce greater ultimate benefit.

In some cases Beer has krown amaurotic blindness to have been cured by an acci dental blow, or fall upon the head, probably removing the pressure of a cataract from the retina, yet who would gravely recommend the infliction of such injuries to remove amanrosis. Apply this reasoning to the occasional success of emetics in some purely sympathetic cases, tho' $\mathrm{gh}$ of directly injurious tendency, and producing an evil accidentally temporary. Who, then, will venture to prescribe them in amaurotic relapses, from whatever cause, which I have shown regularly to degenerate into a mixed character? The proceeding will be truly perilous in proportion to the quantum of the organic or truly local character, in the mixed affection.

\section{EFFECTS OF A LEECH IN THF} INTESTINAL CANAL.

\section{To the Editor of The LanceT.}

SIr:-If you consider the following curious case worthy of a place in your Journal, I shall feel obliged by its insertion. I am, Sir, your obedient servant,

108, Great Portland-street,

Henry R. Wotton. Oct. 24, 1838. 
J. A., a little girl, three years of age, residing at 94, Clipstone-streel, Fitzroysqunre, became a patient of mine in November, 1837 ; she was a healthy-looking robust child, with whom one could find no fault, except that she was not so strong upon her legs as she might be, while the abdomen was tense and tumid; her head, spine, and limbs were well developed, and free from sign of rickets. I learnt that the child had had several attacks such as I now witnessed; by one person she was supposed to suffer from disease of the brain, by others from mesenteric disease, and many thought worms were the cause of mischief, in which latter opinion I concurred. When I first saw her I found that there was much fever, hot and dry skin, sleep disturbed by frequent moanings, grinding of teeth, \&c., eyes but partially closed; she referred the pain to the head and belly; to the latter the hand was frequently applied with the words " pain mama." After a few days' treatment with calomel and scammony, and the acetate of anmonia mixture, the bowels having passed a grood deal of viscid slime of different colours, the fit went off, leaving the tongue, which was before dry and much coated with a brown fur, clean. Though the knotted mucus seemed to form such a nidus for worms, none could be detected; however, the bowels had regained their tone, the belly became much softer and smaller, and the patient was thought well.

These attacks continued to recur at about the interval of a month, for several times, with nearly the same treatment, excepting that latterly $I$ gave the mercury and chalk with rhubarb and cinnamon for a more continued time. On the 6th of April I wa's requested to attend quickly, and found that, the child having complained of much "pricking," the powder had been given more frequently, and in consequence a quantity of bloody lymph-like matter had been evacuated, and with it a living leech; relief soon followed, and since that time the little patient has thrived remarkably, and been free from molestation.

It is worthy of notice that for some hours up to the time this unexpected visitor appeared the pricking was incessant about the rectum. It is what $I$ should call a horse leech, of a dark brown colour, without spots, belly clay colour; its size is that of sn ordinary leech; the mouth does not appear triangular as that of the hirudo medicinalis, but sharp like that of the Jumbricus teres; it lived a week, during which time it swam about in the undulating manner which leeches do. I still have it in my possession.

I made particular inquiries as to whether any water had been added to the vessel, and was assured by the mother and servant that it was perfectly clean and dry previously, and no one had been near it but the child; that immediately afterwards they perceired the "thing" to extricate itself from thr gelatinous matter, and climb up the side in the vessel.

I find that the child, with an elder brother, had often been in the habit of getting to the water-butt, each assisting the other to dring from the $\operatorname{tap} ; I$ have no doubt but the leech, perhaps when small, was swallowed in this manner, and had been the cause of considerable irritation, producing sympa. thetic disturbance of the brain.

I recollect two cases being recorded, I think, in Thr Lancer, where leeches lised in the human stomach; in one the man was supposed to die from rupture of a vessel and a leech was found in the stomach with a large quantity of bloor ; in the other case, a large leech was coughed up durigg violent paroxysm, and the man lived.

At my request the water has been closely inspected when drawn, and a leech has been found in every respect like that referred to, but somewhat less, and not knotted, which is the case in the former one.

\section{POISONING WITH OXIDE OF ARSENIC.}

To the Editor of THE LANCET.

SIR:-On Friday, the 21st of September, an inquest was held before Mr. Brown, the Coroner of Nottingham, on the body of Thomas Adcock, who died at 20 'clock in the morning, from the effects of oxide of arsenic, taken (so far as can be ascertained from the evidence) about a quarter before 8 o'clock on Thursday evening. As it was not then known that he had died from poison. and as no testimony could be obtained as to the cause of his death, $I$ was requested to make an examination of the body, and give evidence. As I consider the appearane: interesting, both as regards the more inme. diate effects of the poison upon the stomad and the remote effects upon the brain lungs, heart, \&c., I have much pleasure ir transmitting an account of them to you fo insertion in THE LANCET. It wonld hart been still more interesting if $I$ could har given you an account of the symptoms dut ing life, but as I did not see him until afte death, I am unable to do so.

The hypertrophy of the heart, and th softening of the thalami and corpora striata were, no doubt, previously existing states I am, Sir, your obedient servant, JOSEPH ThOMSON, Surgeon to the Nottingham Dispensis!

Head. The sinuses of the brain were fil of black blood, and there was slight serot effusion into the cavity of the arachnor and lateral ventricles, and a little also unde the arachnoid, and at the upper part of th posterior lobes of the cerebrum, near to th 